\title{
Validation of CryoSat Sea-Ice Products: Instruments and Methods
}

\author{
C. Haas \\ Alfred Wegener Institute of Polar and Marine Research \\ Bussestrasse 24 \\ D-27570 Bremerhaven, Germany \\ chaas@awi-bremerhaven.de
}

\begin{abstract}
Sea-ice properties like ice and snow density, freeboard, thickness, roughness, and their measurement are described in the context of ground-truth studies for the validation of CryoSat measurements. Both ground-based and airborne methods are presented.
\end{abstract}

\section{INTRODUCTION}

In April 2004, ESA will launch its first Earth Explorer Opportunity Mission "CryoSat". CryoSat is a radar altimeter mission dedicated to determine the thickness and mass balance of the earth's polar ice fields, i.e. continental ice sheets and sea ice. One primary objective of CryoSat is to test the prediction of thinning of Arctic sea ice due to global warming.

CryoSat's Synthetic-Aperture, Interferometric Radar Altimeter (SIRAL) uses new technology particularly developed for sea-ice measurements. Operated in SyntheticAperture (SAR) mode, it possesses high along-track spatial resolution and is therefore well capable of distinguishing between ice floes and open water leads. Therefore, better estimates of ice freeboard, i.e. the height of the ice or snow surface above the local water level, are possible than with conventional pulse-limited radar altimeters. Ice thickness is derived from freeboard by assuming isostatic equilibrium and a certain ice and snow density as well as snow depth. Typical sea ice and snow densities are 890 and $290 \mathrm{~kg} / \mathrm{m}^{3}$, respectively, while snow depth ranges between 0.2 and 0.4 $\mathrm{m}$, depending on region and season $[1,2]$.

Typical mean ice thicknesses in the Arctic range between 2 and $6 \mathrm{~m}$. The range of expected thickness changes is in the order of some decimeters. Therefore, a freeboard retrieval accuracy of a few centimeter is imperative. This requirement is a challenge for satellite radar altimetry, and the uncertainties can be quite large. The freeboard retrieval is complicated by the heterogenous nature of the ice surface, which is rough on the centimeter and decameter scale, with level sections alternating with pressure ridges or rubble fields. Therefore, to judge the performance and accuracy of the freeboard retrievals, and to improve the used retrieval algorithms, extensive ground-based or airborne validation studies are necessary.

This paper describes some of the main measurement techniques which will be applied by Alfred Wegener Institute and others and the derived data products for the purpose of CryoSat validation. Most measurements will be performed on a daily basis using an icebreaker as a platform. Only some surveys can be carried out by means of land-based airplanes or large helicopters (Table 1).

\section{MEASUREMENTS AND TyPiCAL DATA PRODUCTS}

The accuracy of CryoSat thickness retrievals is subject to errors due to, among others, snow loading as well as snow and ice density uncertainties, the floe surface topography, airsnow scattering, the differing character of ice and ocean echoes, and preferential sampling of large floes [3]. Any validation activity has to address some of these uncertainties. Table 1 summarizes these uncertainties and the measurements planed to better determine them.

\section{A. Snow Density Measurements}

Snow density can only be measured by weighting a snow sample with a known volume, typically some 0.51 . Vertical profiles can be measured with a resolution of $0.05 \mathrm{~m}$. However, we will also determine snow density by means of dielectric resonator measurements [4]. As snow density varies significantly both vertically and laterally, many snow pit measurements will be required.

TABLE 1

Main Sea-Ice Retrieval Uncertainties [3] And Measurement Techniques

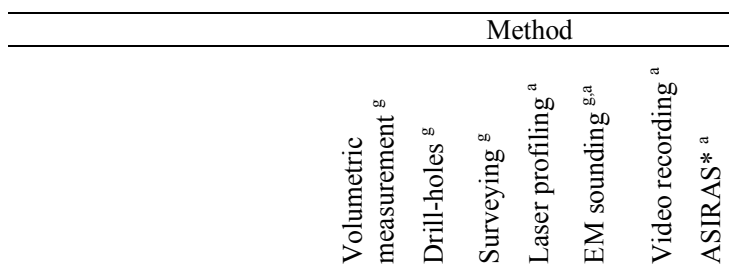

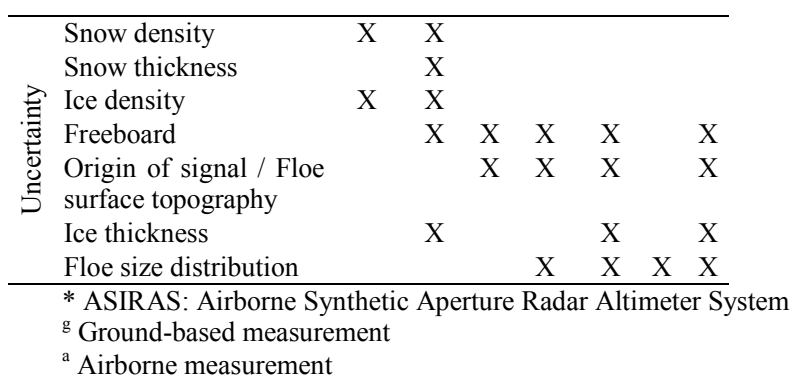


It should be noted that Arctic sea ice is usually snow-free in summer [1]. Instead, the surface is covered by a layer of weathered ice. The properties of this layer will be treated just like snow properties. However, the interface between weathered layer and the underlying ice is less well defined.

\section{B. Snow Thickness Measurements}

Mean snow thickness and its variability will be measured by means of a ruler stick or drill holes along extended profiles. Snow is considerably thicker around pressure ridges than on level ice and thus modifies surface roughness. As the freeboard retrieval might depend on surface roughness, the snow thickness distribution not only modifies the real freeboard, but also contributes to the SIRAL-retrieval errors.

\section{Ice Density Measurements}

Vertical profiles of ice density will be obtained from weighting ice core samples of known volume. As with snow, ice density is quite variable both vertically and laterally [1].

Another possibility to derive bulk ice and snow densities is from measurements of ice draft and freeboard, either by drilling or by combined EM sounding and freeboard surveying (see below and Fig. 1). By assuming isostatic equilibrium, bulk ice and snow density $\rho_{i}$ is then calculated from draft $d$ and freeboard $f$ as

$$
\rho_{i}=\rho_{w} d /(d+f)
$$

with water density $\rho_{w}=1024 \mathrm{~kg} / \mathrm{m}^{3}$. E.g., in Fig. 1 the mean drill-hole freeboard and draft are $0.23 \mathrm{~m}$ and $1.91 \mathrm{~m}$, respectively, corresponding to a bulk density of $913 \mathrm{~kg} / \mathrm{m}^{3}$ (1).

\section{Surveying}

The most accurate means to directly measure freeboard on the ice is by surveying. We use an automatic laser leveling device, which allows for surveys along profiles of some hundred meters length with high lateral resolution. The first $200 \mathrm{~m}$ of the profile shown in Fig. 1 has been thus obtained. Fig. 2 shows the corresponding freeboard distribution. Note that at the end of the Arctic ablation season (August and September) the surface of most melt ponds is at sea level. Therefore, the freeboard distribution has a strong peak at $0.00 \mathrm{~m}$, although ice thickness is not zero, which would erroneously follow by assuming local isostatic equilibrium. The freeboard distribution also shows that melt ponds significantly increase decimeter-scale surface roughness at the end of summer, affecting CryoSat freeboard retrievals.

Surveying is tedious and does not allow to obtain very long profiles within a short time. This is better achieved by airborne laser profiling, but with less accuracy (see Sect. F).

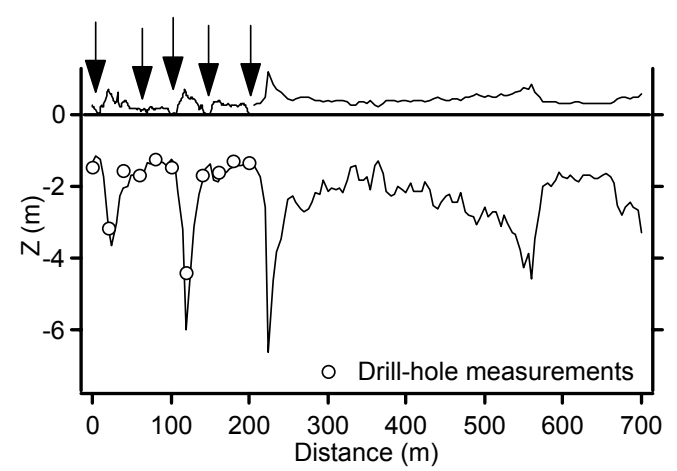

Fig. 1. Typical ground-based EM thickness profile, converted into profiles of freeboard (dashed) and draft (solid). Sea level at $Z=0.00 \mathrm{~m}$. Freeboard along the first $200 \mathrm{~m}$ of profile was obtained by surveying. Arrows indicate locations of melt ponds.

\section{E. Ice Thickness Measurements}

As the ultimate goal of CryoSat is ice thickness mapping, direct thickness measurements provide the best means to validate CryoSat products. Most thickness data today have been collected by upward looking sonars, either mounted on oceanographic moorings or military submarines. However, recently we have operationalized electromagnetic (EM) induction sounding for ice thickness measurements $[5,6]$. The method is robust both during summer and winter, and enables to perform flexible and repeatable surveys. The agreement with drill-hole measurements over level ice is well within $0.1 \mathrm{~m}$, while EM sounding may underestimate the thickness of ridges by as much as 30 to $40 \%$ in the worst cases [5].

EM profiling can be performed on the ice, by pulling a sledge equipped with an EM sensor. This way kilometer-long profiles can be obtained of single floes (Fig. 1). However, due to difficult accessibility, we cannot easily measure thin ice or small floes, or move to another floe. However, the measurements are sufficient to yield representative information about the regional thickness distribution of large floes.

To enable extended profiles with lengths of several tens of kilometers, we have developed an EM sensor which is towed below a helicopter at heights of 10 to $20 \mathrm{~m}$ above the ice surface ("HEM Bird", Fig. 3). With this bird, representative regional thickness distributions can be derived with high vertical and lateral resolution, including open water and thin ice fractions (Fig. 4). As the bird data include small and

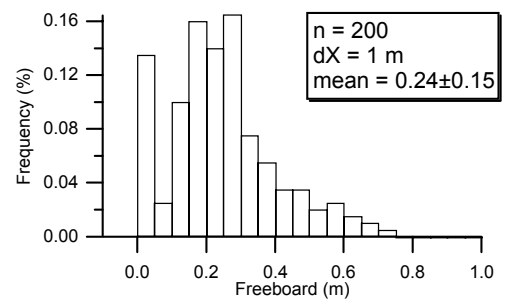

Fig. 2. Frequency distribution of 200 freeboard measurements obtained by surveying of the first $200 \mathrm{~m}$ in Fig. 1. 
large floes, they are well capable to answer if CryoSat data are biased towards large floes due to the problems involved with mixed water/ice radar altimeter measurements [3].

Airborne EM profiles can be performed synchronously with CryoSat overflights.

\section{F. Airborne Laser Profiling}

The HEM Bird includes a laser altimeter measuring the distance between the bird and the ice surface. Laser altimeters are also operated from helicopters or fixed-wing aircrafts directly. If the height of the aircraft above the water level is exactly known, the laser measurements provide direct estimates of freeboard. However, as aircraft altitudes are quite variable over length scales of several kilometers, exact altitude measurements, e.g. by inertial navigation systems or differential GPS, are required.

Laser altimeter measurements also provide information on surface roughness and pressure ridge statistics, which are required to assess the origin of CryoSat echoes and the interpretation of the freeboard retrieval [3].

\section{G. Airborne Video Recording}

The airborne measurements described above yield line data, i.e. one-dimensional information along the flight track. Video recording will be performed to derive additional areal information of the measured parameters. In particular, floe size distributions and melt pond coverage can be determined from video footage. These are important to investigate the origin and character of CryoSat echoes [3].

\section{H. Airborne Synthetic-Aperture Interferometric Radar System (ASIRAS)}

ASIRAS is the airborne version of CryoSat's SIRAL instrument. It will be flown by fixed-wing aircraft, both over glacial and sea ice. With ASIRAS, synchronous flights will be performed with CryoSat. However, ASIRAS provides the opportunity to perform independent ground-truth studies jointly with the other instruments described above to validate the origin and character of synthetic-aperture radar altimeter signals and freeboard retrievals.

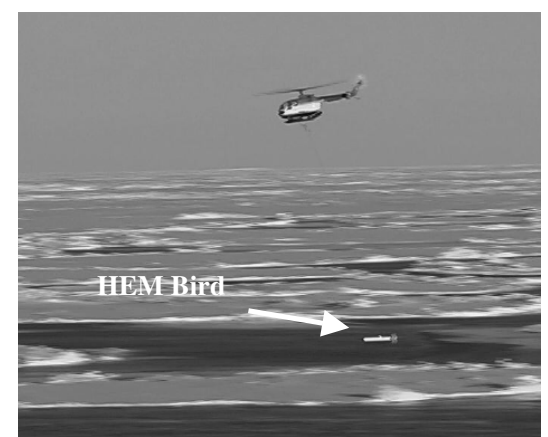

Fig. 3. Photograph of HEM Bird sounding ice tickness.

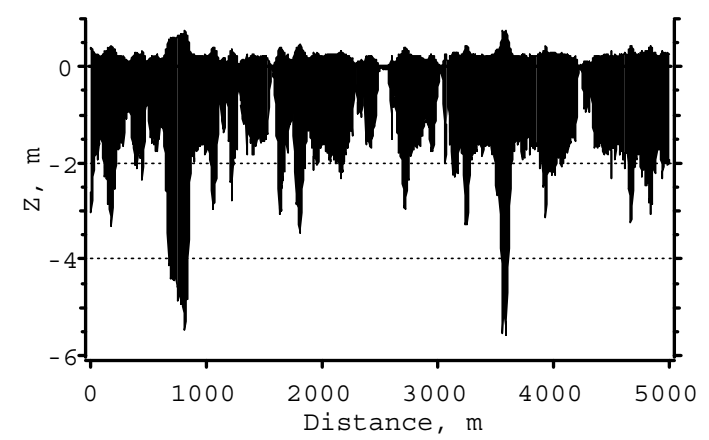

Fig. 4. Typical $5 \mathrm{~km}$ long HEM Bird thickness profile.

\section{CONCLUSION AND OUTLOOK}

The measurements and systems described above provide powerful tools for validation of CryoSat measurements, addressing many of the uncertainties of the freeboard retrieval [3]. They will provide extensive ground-truth, and are well capable of delineating different ice regimes. However, reaching the same accuracy as CryoSat should nominally deliver is challenging. On the other hand, CryoSat reaches its accuracy only if measurements are averaged over larger regions $\left(>10^{4} \mathrm{~km}\right)$ and longer periods ( $>1$ month) [3] If possible, validation campaigns should also cover these spatial and temporal scales.

Additional sensors would be desirable like Ku-band scatterometers or snow radars to even better investigate radar/ice interactions, and fixed-wing aircraft EM sensors for larger scale thickness surveys. Direct freeboard measurements by means of laser altimeter and ASIRAS would benefit from still-to-be improved aircraft altitude measurements with inertial navigation platforms or differential GPS.

\section{ACKNOWLEDGEMENT}

We gratefully acknowledge validation support by German Research Ministry and DLR as well as by ESA.

\section{REFERENCES}

[1] H. Eicken, M. Lensu, M. Leppäranta, W.B. Tucker, A.J. Gow, and O. Salmela, "Thickness, structure and properties of level summer multiyear ice in the Eurasian Sector of the Arctic Ocean", J. Geophys. Res., 100 (C11), 22,697-22,710, 1995.

[2] S.G. Warren and 6 others, "Snow depth on Arctic sea ice", J. Climate, $12,1814-1829,1999$.

[3] D.J. Wingham and 9 others, CryoSat calibration and validation concept, ESA Document CS-PL-UCL-SY-0004, 91 pp., 2001.

[4] A. Shivola and M. Tiuri, "Snow Fork for field determination of the density and wetness profiles of a snow pack", IEEE Transactions on Geoscience and Remote Sensing, GE-24(5), 717-721, 1986.

[5] C. Haas, S. Gerland, H. Eicken, and H. Miller, "Comparison of sea-ice thickness measurements under summer and winter conditions in the Arctic using a small electromagnetic induction device", Geophysics, 62 (3), 749-757, 1997.

[6] C. Haas and H. Eicken, "Interannual variability of summer sea ice thickness in the Siberian and Central Arctic under different atmospheric circulation regimes", J. Geoph. Res., 106 (C3), 4449-4462, 2001. 